\title{
Reliability and agreement of the central and mid-peripheral corneal thickness measured by a new Scheimpflug based imaging
}

\author{
A-Yong Yu ${ }^{1,2 \#}$, Junming Ye ${ }^{1 \#}$, Giacomo Savini ${ }^{3}$, Yiran Wang ${ }^{1}$, Tianjiao Zhang ${ }^{1}$, Min Chen $^{1}$, \\ Qinmei Wang ${ }^{1,2}$, Jinhai Huang ${ }^{1,2}$
}

${ }^{1}$ Eye Hospital and School of Ophthalmology and Optometry, Wenzhou Medical University, Wenzhou, China; ${ }^{2}$ State Key Laboratory of Optometry, Ophthalmology and Vision Science, Wenzhou, China; ${ }^{3}$ G.B. Bietti Foundation IRCCS, Rome, Italy

Contributions: (I) Conception and design: AY Yu, J Ye, Q Wang, J Huang; (II) Administrative support: Q Wang, J Huang; (III) Provision of study materials or patients: AY Yu, J Ye; (IV) Collection and assembly of data: Y Wang, T Zhang, M Chen; (V) Data analysis and interpretation: AY Yu, G Savini, J Huang; (VI) Manuscript writing: All authors; (VII) Final approval of manuscript: All authors.

\#These authors contributed equally to this work.

Correspondence to: Prof. Qinmei Wang, MD; Jinhai Huang, MD, PhD. Eye Hospital of Wenzhou Medical University, 270 West Xueyuan Road, Wenzhou, China. Email: wqm6@mail.eye.ac.cn; vip999vip@163.com, vip9999vip@wmu.edu.cn.

Background: To assess the intra-observer repeatability and inter-observer reproducibility of central corneal thickness (CCT) and mid-peripheral corneal thickness (MPCT) measurements using a new Scheimpflug imaging instrument (Scansys) and compare the agreement with the rotating Scheimpflug corneal tomographer (Pentacam HR).

Methods: The same well-trained operator performed the measuring using the two devices, after which Scansys measurements were repeated by another operator. Both instruments required three consecutive measurements per subject. Corneal thickness measurements were obtained by each instrument, including CCT, thinnest corneal thickness (TCT), pupil corneal thickness (PCT), and MPCT. Test-retest repeatability (TRT), within-subject coefficient of variation (CoV), and intra-class correlation coefficient (ICC) were used to evaluate repeatability and reproducibility. A paired t-test was used to compare the differences between Scansys and Pentacam, and the agreement was compared with Bland-Altman plots.

Results: This study enrolled 112 healthy subjects. The CoV were $<0.91 \%$ and $0.55 \%$ for repeatability and reproducibility, respectively. The ICC was close to 1 in all measurements. For intra-observer repeatability in the $\mathrm{CT}_{2 \mathrm{~mm}}$ region, TRT was $<10.30 \mu \mathrm{m}$. Moreover, TRT was $<15.26 \mu \mathrm{m}$ within the $\mathrm{CT}_{5 \mathrm{~mm}}$ region. The paired $t$-test showed significant differences in all corneal thickness measurements $(\mathrm{P}<0.001)$. The central region and $\mathrm{CT}_{2 \mathrm{~mm}}$ agreement were high, but the largest range of $95 \%$ limits of agreement (LoA) appeared in the $\mathrm{CT}_{\text {nasal-5mm }}$.

Conclusions: The new Scheimpflug imaging instrument showed excellent intra-observer repeatability and inter-observer reproducibility for corneal thickness measurements. The agreement analysis suggested that Scansys and Pentacam could be interchangeably used between the central region and $\mathrm{CT}_{2 \mathrm{~mm}}$, except $\mathrm{CT}_{5 \mathrm{~mm}}$.

Keywords: Scheimpflug; agreement; reliability; corneal thickness; biometry

Submitted Dec 13, 2020. Accepted for publication Apr 24, 2021.

doi: 10.21037/atm-20-7895

View this article at: https://dx.doi.org/10.21037/atm-20-7895 


\section{Introduction}

Corneal thickness has an important role in predicting glaucoma (1), the diagnosis of keratoconus (2), and the assessment of corneal edema (3). In refractive surgery, accurate preoperative measurement of corneal thickness, such as central corneal thickness (CCT) and midperipheral corneal thickness (MPCT) can be used to assess the feasibility of surgery, thereby reducing the incidence of postoperative ectasia $(2,4)$. Yet, there is a significant difference in the thickness of the cornea from the center to the periphery when measured using different devices, such that measurements further away from the center result in the greater the difference (5). In addition, peripheral corneal thickness has to be obtained for the diagnosis of keratoconus and other corneal ectasia, in the postoperative follow-up of corneal edema, and in the planification of corneal relaxing incisions (6-8).

Scheimpflug image analysis is a precise technique that is commonly applied for light scattering measurements and biometric measurements of the anterior segment (9). Repeatable data on the characteristics of the anterior segment have been provided in clinical and experimental studies. Several instruments based on this technique have been marketed, including Pentacam (Oculus, Wetzlar, Germany), Sirius (CSO, Florence, Italy), and Galilei (Ziemer, Port, Switzerland), while their precision, repeatability, and agreement have been well validated (10-12).

Scansys (MediWorks, Shanghai, China) is a novel device based on Scheimpflug imaging that can be used for anterior segment diagnosis. However, so far, no studies reported on this Scheimpflug based imaging. Consequently, the aim of this study was to evaluate the intra-observer repeatability and inter-observer reproducibility of the central and mid-peripheral regional corneal thickness and compare the agreement of these measurements between Scansys and Pentacam to determine the equivalence and interchangeability in healthy subjects. We present the following article in accordance with the STARD reporting checklist (available at https://dx.doi.org/10.21037/atm-207895).

\section{Methods}

\section{Subjects}

This prospective study recruited healthy subjects from the Eye Hospital of Wenzhou Medical University. After a detailed explanation of the purpose of the study, informed consent was provided by all patients. The study was conducted in accordance with the Declaration of Helsinki (as revised in 2013) and was approved by the Office of Research Ethical Committee, Eye Hospital of Wenzhou Medical University (No. KYK2013-21). Informed consent was obtained from all individual participants. Exclusion criteria included active ocular disease or trauma, dry eye, previous ocular surgery, and the history of wearing contact lenses (for soft contact lenses less than two weeks, rigid contact lenses less than four weeks).

\section{Instruments}

The Scansys is a new corneal topography instrument that uses the Scheimpflug camera, which can obtain 107,520 data points and 28 slit images in high resolution $(1,280 \times 1,024)$ of the anterior and posterior surface of the cornea in just 1 second per measurement, and has a faster scan speed. This instrument uses a slit-light source with a wavelength of $470 \mathrm{~nm}$. The horizontal measurement range is up to $14 \mathrm{~mm}$, and the vertical measurement range is up to $10 \mathrm{~mm}$. Meanwhile, it can track the inevitable micromovements of the eye and reduce motion error by correcting eye motion through a software algorithm. It provides anterior and posterior corneal topography, including cornea curvature maps, cornea thickness maps, cornea elevation maps, etc.

The Pentacam HR (Oculus, Wetzlar, Germany) is one of the first commercially available rotating Scheimpflug cameras, which takes 25 slit images composed of 138,000 points per measurement in less than 2 seconds. It can generate a 3-dimensional image of the anterior segment and provide measurements of the corneal curvature, central and peripheral corneal thickness, and anterior chamber depth.

\section{Procedures}

The two devices were used to measure the right eye of all subjects in random order. To assess reliability and agreement, the measurements by the two devices were performed by the same well-trained operator. Then, Scansys measurements were repeated by another operator to investigate the inter-operator reproducibility. Both devices were used to perform three consecutive measurements from each subject. Before each measurement, the patient was asked to blink to smooth the tear film. To ensure the independence of each measurement, subjects were asked to sit back while the operator readjusted the joystick. All measurements were taken between $10 \mathrm{AM}$ and $5 \mathrm{PM}$ to 
minimize the diurnal change of corneal thickness. The operating procedure strictly followed the manufacturer's guidelines. If the "quality specification" was "OK", the examination was included in the analysis; otherwise, the procedure was repeated.

Corneal thickness measurements included CCT, thinnest corneal thickness (TCT), and pupil corneal thickness (PCT). At positions $1 \mathrm{~mm}$ and $2.5 \mathrm{~mm}$ away from the corneal apex, 8 points were collected in the nasal, superior, temporal, and inferior quadrants: these were defined as $\mathrm{CT}_{2 \mathrm{~mm}}\left(\mathrm{CT}_{\text {nasal- }}\right.$ ${ }_{2 \mathrm{~mm}}, \mathrm{CT}_{\text {superior-2mm }}, \mathrm{CT}_{\text {temporal-2mm }}$, and $\left.\mathrm{CT}_{\text {inferior-2mm }}\right)$ and $\mathrm{CT}_{5 \mathrm{~mm}}$ $\left(\mathrm{CT}_{\text {nasal-5mm }}, \mathrm{CT}_{\text {superior-5mm }}, \mathrm{CT}_{\text {temporal-5mm }}\right.$, and $\left.\mathrm{CT}_{\text {inferior-5mm }}\right)$, respectively.

\section{Statistical analysis}

The data were analyzed by SPSS (version 21.0, IBM Corp.) and EXCEL (2010, Microsoft Corp.). Mean and standard deviation (SD) were used to indicate corneal thickness at different locations. Within-subject standard deviation $\left(\mathrm{S}_{\mathrm{w}}\right)$, test-retest repeatability $\left(\mathrm{TRT}=2.77 \mathrm{~S}_{\mathrm{w}}\right)$, within-subject coefficient of variation $(\mathrm{CoV})$, and intra-class correlation coefficient (ICC) were used to evaluate repeatability and reproducibility. A paired t-test was used to compare the measurements by the two devices, and agreement between Scansys and Pentacam was evaluated with Bland-Altman plots and the $95 \%$ limits of agreement (LoA). These were defined as the average difference between the two devices \pm 1.96 SD (13). A P value $<0.05$ was considered statistically significant.

\section{Results}

A total of 112 right eyes from 112 subjects (29 female and 83 male) were included in the current study. The mean age $\pm \mathrm{SD}$ was $26 \pm 5.58$ (range, 18 to 43 ) years, and the equivalent spherical power \pm SD was $-5.78 \pm 2.39$ (range, -1.25 to -11.75 ) diopters (D).

Table 1 shows the intra-observer repeatability of corneal thickness measurements for each observer with the new Scheimpflug camera. For all measurements, the ICC was close to 1 , which indicated high intra-observer repeatability. The repeatability of central and $\mathrm{CT}_{2 \mathrm{~mm}}$ regions was higher than that of $\mathrm{CT}_{5 \mathrm{~mm}}$. In $\mathrm{CT}_{2 \mathrm{~mm}}$ measurements, the TRT was lower than $10.3 \mu \mathrm{m}$, whereas, in $\mathrm{CT}_{5 \mathrm{~mm}}$, it was less than $15.5 \mu \mathrm{m}$. The $\mathrm{CoV}$ within $\mathrm{CT}_{2 \mathrm{~mm}}$ was less than $0.7 \%$ and within $\mathrm{CT}_{5 \mathrm{~mm}}$ was less than $1 \%$.

Table 2 shows the inter-observer reproducibility of corneal thickness measurements. TRT showed an increasing trend from the center to the periphery. Nevertheless, the reproducibility of all the positions was excellent, with only slight deviations in the $\mathrm{CT}_{\text {superior-5mm }}$ and $\mathrm{CT}_{\text {inferior-5mm }}$ $\left(\mathrm{CT}_{\text {superior-5mm }}\right.$ : TRT $=9.09 \mu \mathrm{m}, \mathrm{COV}=0.54 \% ; \mathrm{CT}_{\text {inferior-5mm: }}$ TRT $=8.90 \mu \mathrm{m}, \mathrm{COV}=0.55 \%)$. The $\mathrm{ICC}$ values for all measurements exceeded 0.989 .

Table 3 indicates the differences and agreement between Scansys and Pentacam. The paired t-test of the two instruments showed statistically significant differences at all locations $(\mathrm{P}<0.001)$. In the central and $\mathrm{CT}_{2 \mathrm{~mm}}$ region, the value of Scansys was slightly larger than Pentacam in measuring corneal thickness, except for the $\mathrm{CT}_{\text {nasal-2mm. }}$ In $\mathrm{CT}_{5 \mathrm{~mm}}$, the value of Scansys was smaller than Pentacam.

The agreement analysis of Bland-Altman plots is shown in Figures 1-4. The central and $\mathrm{CT}_{2 \mathrm{~mm}}$ region had a smaller range than the $\mathrm{CT}_{5 \mathrm{~mm}}$. Yet, the most significant difference appeared in the $\mathrm{CT}_{\text {nasal-smm. }}$.

\section{Discussion}

Scheimpflug technology is widely used in the pre-operative and post-operative settings as a reliable method for imaging and measuring the anterior ocular segment. The Scansys is the latest model based on Scheimpflug technology; however, before its clinical application can be approved, it is necessary to evaluate whether it provides repeatable and reproducible measurements and whether its measurements are consistent with those given by previously available instruments based on a similar principle.

To the best of our knowledge, this is the first study that evaluated the intra-observer repeatability and inter-observer reproducibility of corneal central and mid-peripheral thickness measurements using the new Scheimpflug imaging Scansys. Since the CoV did not exceed $1 \%$ and the ICC was close to 1 in all quadrants, we concluded that the measurements provided by this new instrument have excellent repeatability and reproducibility. The values of corneal thickness obtained in the current study were similar to other studies on the use of Scheimpflug technology on unoperated eyes (14-16). In the four quadrants, the superior measurements had poorer repeatability, which is similar to previous studies $(16,17)$. Meanwhile, other studies have found that the nasal quadrant is better than the temporal quadrant (18), which was consistent with our results.

The current study found excellent precision of central corneal thickness measurements, which was greatly improved compared with that of Pentacam rotating 
Table 1 Intra-observer repeatability of the new Scheimpflug imaging by each observer in measuring corneal thickness

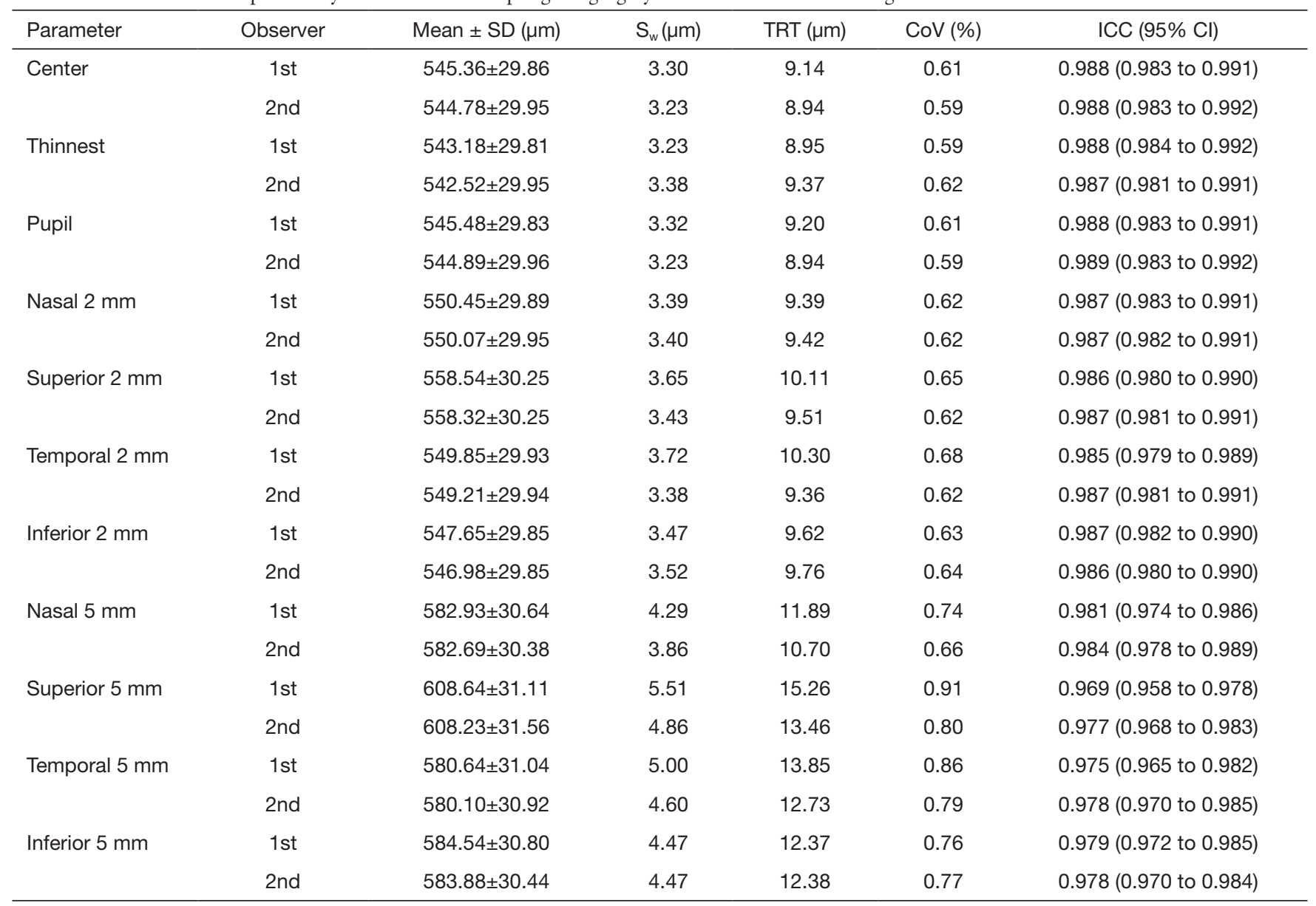

$\mathrm{SD}$, standard deviation; $\mathrm{S}_{\mathrm{w}}$, within-subject standard deviation; TRT, test-retest repeatability $\left(2.77 \mathrm{~S}_{\mathrm{w}}\right)$; CoV, within-subject coefficient of variation; ICC, intraclass correlation coefficient; USP, ultrasound pachymetry.

Table 2 Inter-observer reproducibility of the new Scheimpflug imaging in measuring corneal thickness

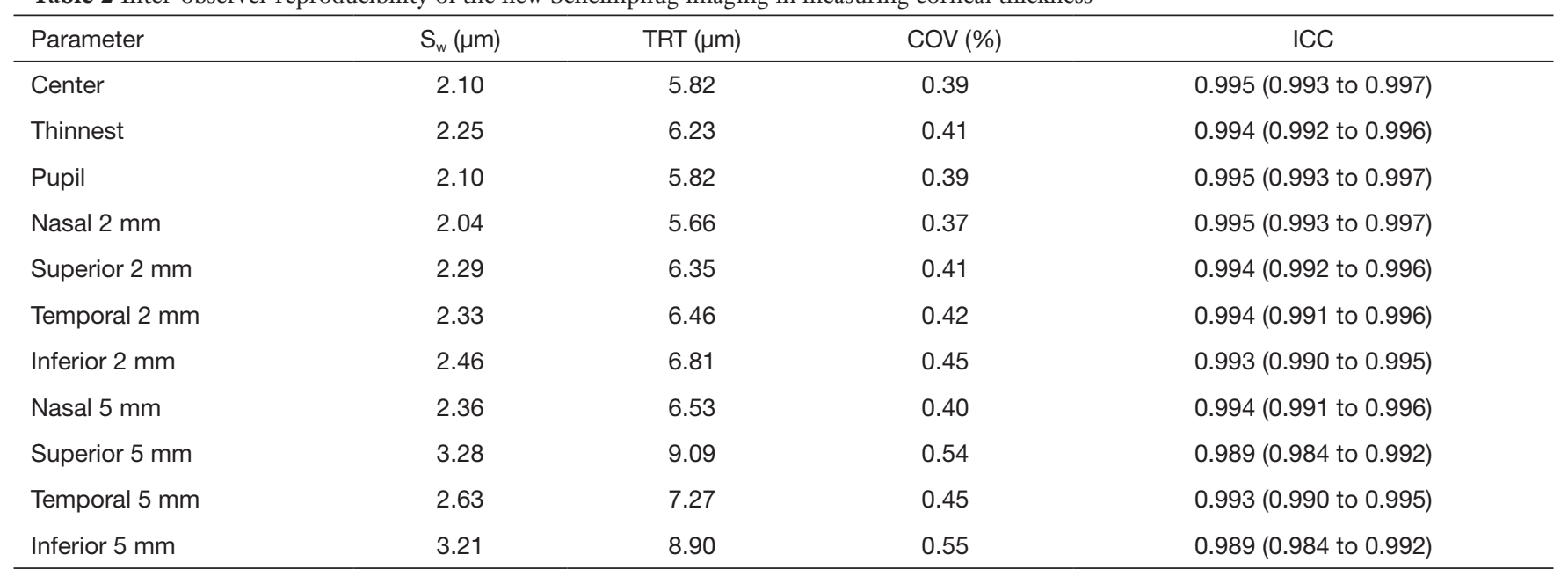

SD, standard deviation; Sw, within-subject standard deviation; TRT, test-retest reproducibility (2.77 Sw); COV, within-subject coefficient of variation; ICC, intraclass correlation coefficient. 
Table 3 Difference and agreement between the new Scheimpflug imaging Scansys and Pentacam HR in measuring corneal thickness

\begin{tabular}{lccc}
\hline Device pairings & Mean \pm SD $(\mu \mathrm{m})$ & P value & 95\% LoA \\
\hline Center & $3.36 \pm 5.11$ & $<0.001$ & -6.65 to 13.37 \\
Thinnest & $4.47 \pm 5.29$ & $<0.001$ & -5.89 to 14.83 \\
Pupil & $3.10 \pm 4.94$ & $<0.001$ & -6.58 to 12.79 \\
Nasal $2 \mathrm{~mm}$ & $-2.68 \pm 5.29$ & $<0.001$ & -13.05 to 7.69 \\
Superior $2 \mathrm{~mm}$ & $0.58 \pm 5.12$ & $<0.001$ & -9.45 to 10.61 \\
Temporal $2 \mathrm{~mm}$ & $5.78 \pm 4.90$ & $<0.001$ & -3.81 to 15.38 \\
Inferior $2 \mathrm{~mm}$ & $2.95 \pm 6.09$ & $<0.001$ & -8.98 to 14.88 \\
Nasal $5 \mathrm{~mm}$ & $-22.35 \pm 6.61$ & $<0.001$ & -35.30 to -9.40 \\
Superior $5 \mathrm{~mm}$ & $-17.83 \pm 7.71$ & $<0.001$ & -32.94 to -2.72 \\
Temporal $5 \mathrm{~mm}$ & $-7.44 \pm 5.83$ & $<0.001$ & -18.87 to 3.99 \\
Inferior $5 \mathrm{~mm}$ & $-7.56 \pm 7.56$ & $<0.001$ & -22.38 to 7.26 \\
\hline
\end{tabular}

$\mathrm{SD}$, standard deviation.

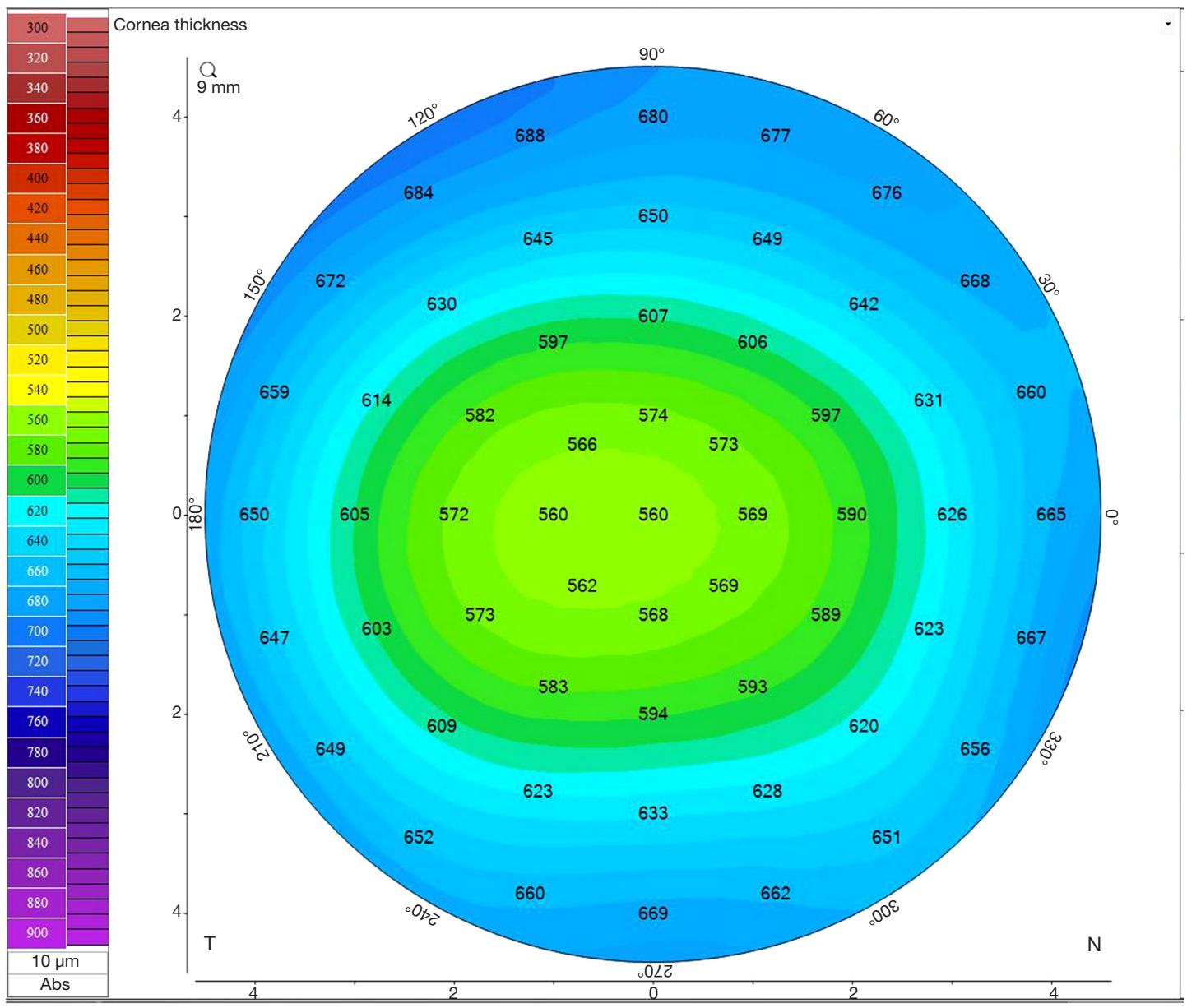

Figure 1 Corneal thickness maps obtained with the new Scheimpflug imaging instrument. 

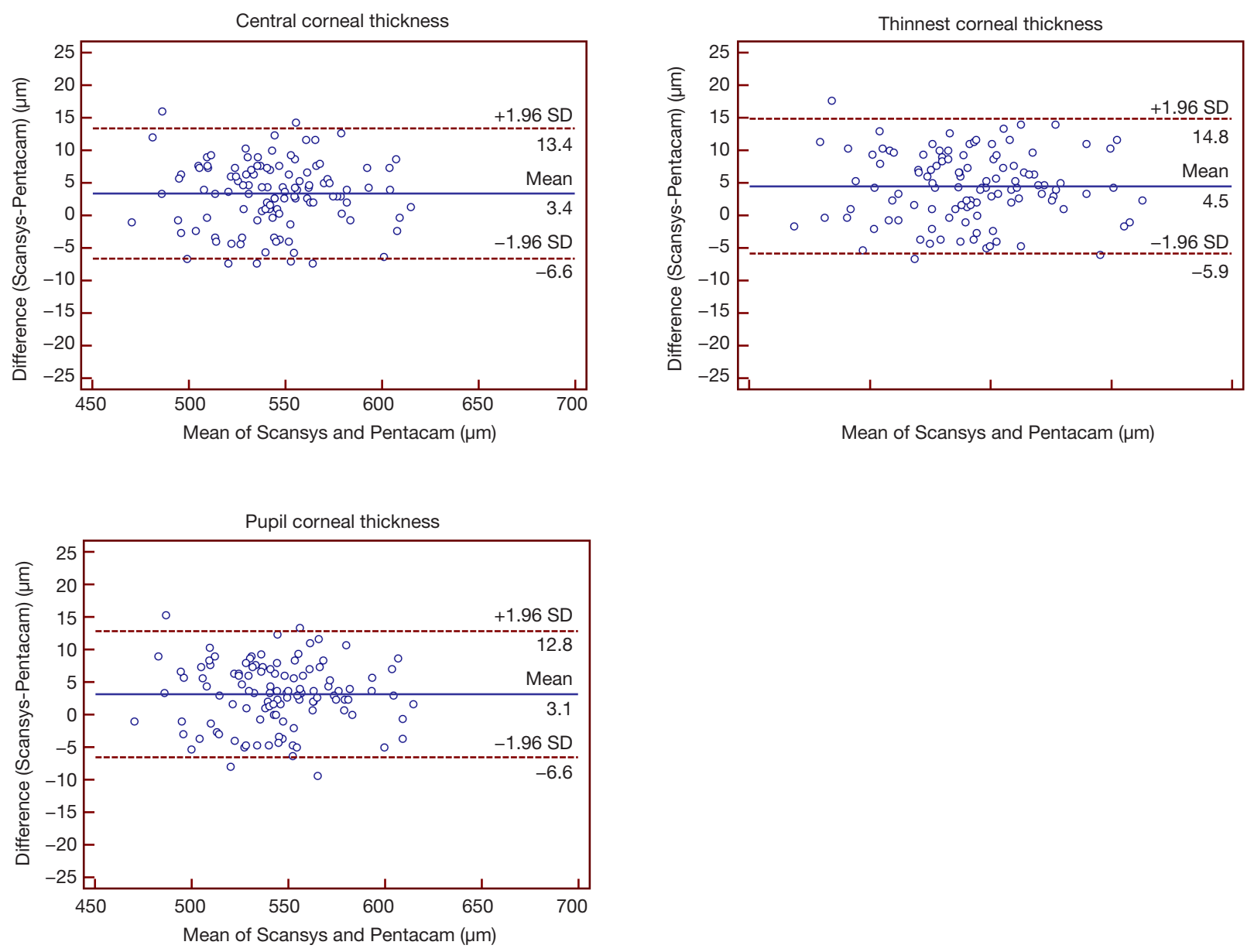

Figure 2 Bland-Altman plots for central corneal thickness (CCT), thinnest corneal thickness (TCT), and pupil corneal thickness (PCT) between the new Scheimpflug imaging Scansys and Pentacam HR. The solid lines = the mean difference; the upper and lower lines = the 95\% LoA; SD, standard deviation.

Scheimpflug camera $(\mathrm{CoV}=0.6-1.7 \%)(15,18)$ and was similar to that of Sirius Scheimpflug camera-Placido topographer $\left(\mathrm{S}_{\mathrm{w}}=2.78-3.17 \mu \mathrm{m}\right)(16,19)$. Besides, Kumar et al. (20) reported higher $\mathrm{Sw}_{\mathrm{w}}(7.15 \mu \mathrm{m})$ and TRT $(19.81 \mu \mathrm{m})$ in TCT measurements with Orbscan II (Bausch \& Lomb, Rochester, NY) compared to our results. However, according to Huang et al. (19), the repeatability for central region with Scansys was lower than Galilei $(\mathrm{CoV}$ $=0.24-0.33 \%$, TRT $=3.64-5.05 \mu \mathrm{m}$ ) and RTVue (Optovue, Freemont, $\mathrm{CA}, \mathrm{CoV}=0.31-0.41 \%$, TRT $=4.57-6.01 \mu \mathrm{m})$. Repeatability was reduced when moving measurements from 2 to $5 \mathrm{~mm}$. The reliability of the MPCT was inferior to that of CCT $(17,21)$, which was consistent with our findings. This may be due to the rotation of the camera around the optical axis, as the overlap of the Scheimpflug images and the number of analyzed points at the center of the cornea are greater than those at the corneal periphery, so the number of points captured at the same location decreased from the center of the cornea to the periphery (17). In a previous study, Huang et al. compared 3 rotating Scheimpflug cameras (Pentacam, Sirius, Galilei) and 1 Fourier-domain optical coherence tomography system (RTVue) (19). In the $5 \mathrm{~mm}$ region, the intra-observer TRT ranged from 14.08 to $19.01 \mu \mathrm{m}$ with Pentacam, from 9.47 to $18.21 \mu \mathrm{m}$ with Sirius, from 11.14 to $19.37 \mu \mathrm{m}$ with Galilei, and from 11.63 to $19.01 \mu \mathrm{m}$ with RTVue, respectively. Moreover, Lu et al. evaluated the mid-peripheral region with RTVue and reported the TRT of 11.77-17.23 $\mu \mathrm{m}$ (22). In the repeatability of Orbscan II assessed by Martin and his team, the CoV of MPCT was $1.11-1.67 \%$ (23). 

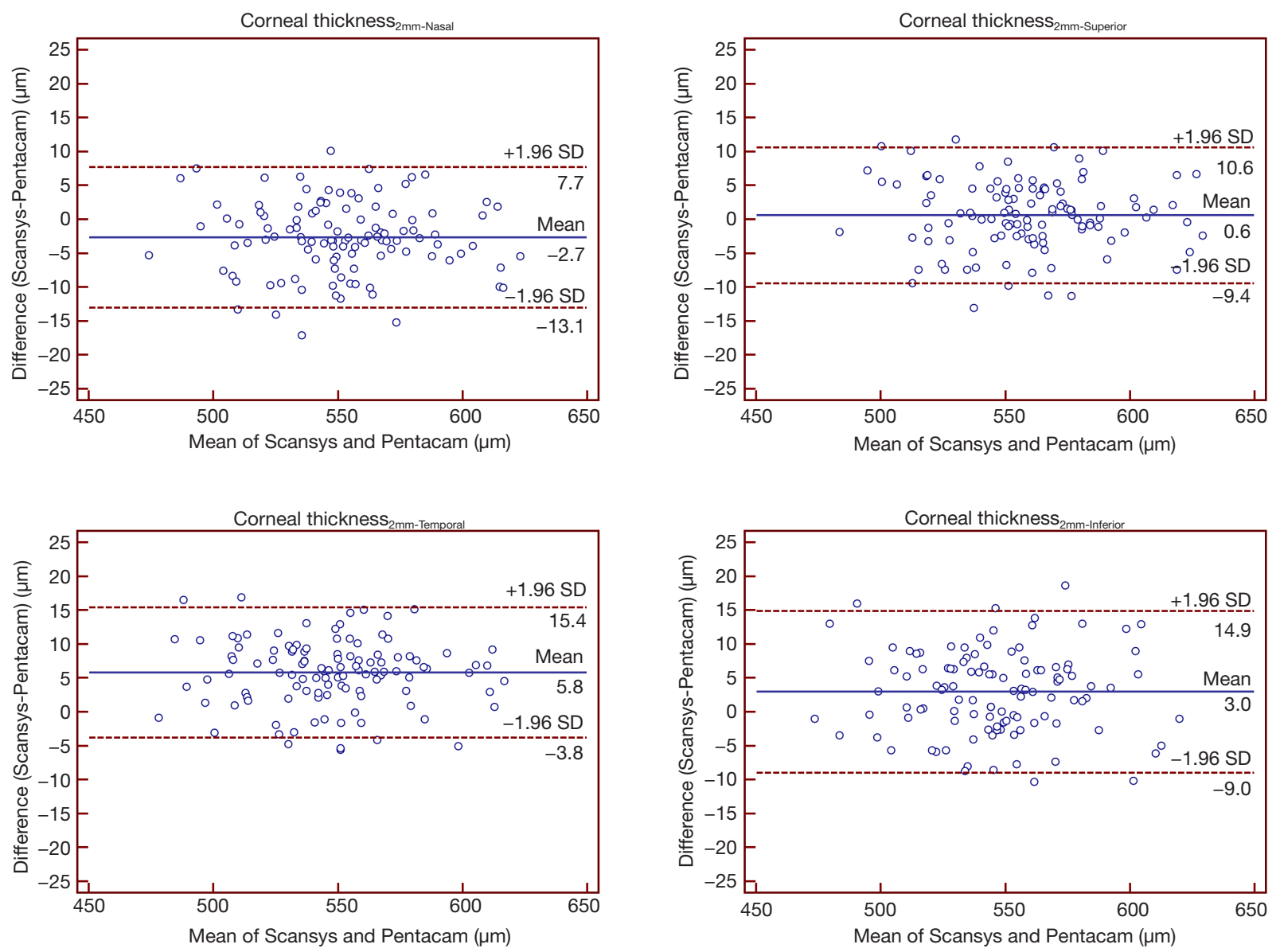

Figure 3 Bland-Altman plots for corneal thickness ${ }_{2 \mathrm{~mm}-\mathrm{Nasal}}\left(\mathrm{CT}_{\text {nasal-2mm }}\right)$, thickness ${ }_{2 \mathrm{~mm}-S \text { uperior }}\left(\mathrm{CT}_{\text {superior-2mm }}\right)$, thickness ${ }_{2 \mathrm{~mm}-\mathrm{Temporal}}\left(\mathrm{CT}_{\text {temporal-2mm }}\right)$, and thickness ${ }_{2 \mathrm{~mm}-\text { Inferior }}\left(\mathrm{CT}_{\text {inferior-2mm }}\right)$ between the new Scheimpflug imaging Scansys and Pentacam HR. The solid lines = the mean difference; the upper and lower lines = the 95\% LoA; SD, standard deviation.

In general, the measurements obtained by the new Scheimpflug instrument in the mid-peripheral region had slightly higher repeatability and advantage compared with several other instruments mentioned above.

Subsequently, we compared the new Scheimpflug imaging with the Pentacam to analyze their agreement. Many previous studies demonstrated the reliability of Pentacam measurements $(6,15)$. In terms of CCT and TCT measurements, Scansys provided slightly higher measurements compared to those obtained by the Pentacam, which was in line with the previous studies showing that the Pentacam underestimated the values of CCT and TCT (24). Furthermore, Anayol et al. reported that the difference between Pentacam and Galilei was -13.93 and $-5.5 \mu \mathrm{m}$ in the CCT and TCT, respectively (25). Moreover, Huang et al. found that the difference between Pentacam and Sirius was -3.3 and $-3.4 \mu \mathrm{m}$ in the CCT and TCT, respectively (26). Thus, compared to other instruments that use a similar principle, the difference between Scansys and Pentacam was slight and could be considered clinically insignificant. The only exceptions were measurements at $5 \mathrm{~mm}$ in the nasal and superior quadrants, where the difference was higher than $15 \mu \mathrm{m}$.

As far as the agreement is concerned, central measurements revealed a high agreement between the two devices, thus suggesting they could be used interchangeably. Previous studies with other Scheimpflug-based instruments reported wider $95 \%$ LoAs than our present results. De la Parra-Colin et al. reported that the $95 \%$ LoAs ranged from -27.7 to $7.5 \mu \mathrm{m}$ in the CCT and from -31.7 to $-6.8 \mu \mathrm{m}$ in 

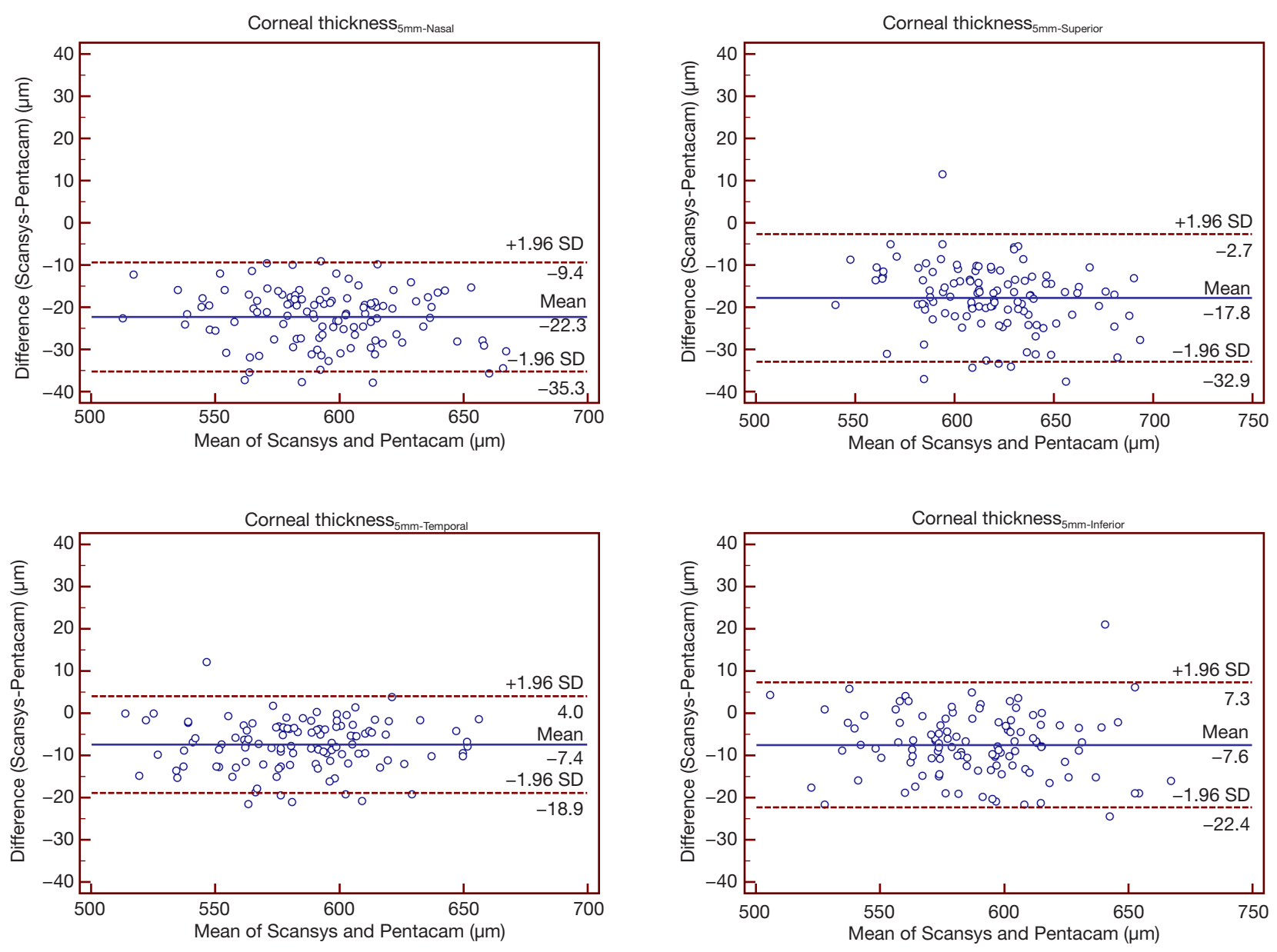

Figure 4 Bland-Altman plots for corneal thickness $s_{5 \mathrm{~mm}-\mathrm{Nasal}}\left(\mathrm{CT}_{\text {nasal-5mm }}\right)$, thickness ${ }_{5 \mathrm{~mm}-\mathrm{Superior}_{1}}\left(\mathrm{CT}_{\text {superior-5mm }}\right)$, thickness ${ }_{5 \mathrm{~mm}-\mathrm{Temporal}}\left(\mathrm{CT}_{\text {temporal-5mm }}\right)$, and thickness ${ }_{5 \mathrm{~mm}-\text { Inferior }}\left(\mathrm{CT}_{\text {inferior-5mm }}\right)$ between the new Scheimpflug imaging Scansys and Pentacam HR. The solid lines = the mean difference; the upper and lower lines = the $95 \%$ LoA; SD, standard deviation.

the TCT when comparing the measurements by Pentacam and Sirius, respectively (27). Similarly, Nasser $e t$ al. reported that the range of LoA was from -9.61 to $33.44 \mu \mathrm{m}$ in the TCT (28). Additionally, 95\% LoAs (from 11.74 to $16.12 \mu \mathrm{m}$ in the CCT and from 3.34 to $7.65 \mu \mathrm{m}$ in the TCT) were also reported by Anayol et al. when comparing Galilei with Pentacam (25).

In addition, we also evaluated the agreement of $\mathrm{CT}_{5 \mathrm{~mm}}$ measurements performed with the two instruments. According to results from a previous study that compared Pentacam and Visante OCT (Zeiss, Dublin, CA), Pentacam provided a larger value of MPCT $(33.4 \pm 2.7 \mu \mathrm{m})(6)$. In the present study, Pentacam also provided a larger corneal thickness measurement in the $\mathrm{CT}_{5 \mathrm{~mm}}$ region. Bland-Altman plots revealed that there was only a moderated agreement in the $\mathrm{CT}_{5 \mathrm{~mm}}$ region between the two devices so that their measurements were not interchangeable. The lower level of agreement in the mid-peripheral region may be due to the image distortion of the Scheimpflug technique in the peripheral region, as shown by previous studies $(17,29)$, and to the different number of scans (28vs. 25) and analyzed data points (107,520 vs. 138,000 points). According to the results of Huang et al., the 95\% LoAs between Scansys and Pentacam were narrower than the results among the RTVue OCT and three Scheimpflug cameras (range approximately $40 \mu \mathrm{m})(26)$. Comparing Sirius and Visante OCT, Milla et al. reported that the wider $95 \%$ LoAs were -7.6 to $59.1 \mu \mathrm{m},-9.2$ to $77.5 \mu \mathrm{m},-24.0$ to $42.8 \mu \mathrm{m},-0.4$ to $51.6 \mu \mathrm{m}$ at nasal, superior, temporal, inferior $2.5 \mathrm{~mm}$ from the center, respectively (16). In another study by Bourges 
et al. (30), a wider range of the 95\% LoAs was also found between Orbscan II and Pentacam (the maximum ranged from -6.2 to $59.8 \mu \mathrm{m}$, the minimum ranged -22.3 to $26.9 \mu \mathrm{m})$. Martin et al. also found a poor agreement (spanning over $130 \mu \mathrm{m}$ ) between Orbscan $I I$ and Ultrasound (23).

This study has a few limitations. First, only young, healthy subjects with normal corneas were examined. Future studies should involve patients who received refractive surgery or with keratoconus. Second, only two devices were evaluated. Future studies should evaluate several other instruments based on Scheimpflug technology at the same time.

In conclusion, the new Scheimpflug imaging Scansys showed high intra-observer repeatability and inter-observer reproducibility of corneal thickness measurements. In terms of agreement with Pentacam, their measurements can be considered interchangeable in the central region and at $2 \mathrm{~mm}$, whereas they cannot be considered interchangeable for measurements at $5 \mathrm{~mm}$.

\section{Acknowledgments}

Funding: This work was supported in part by the Medical and Health Science and Technology Program of Zhejiang Province (2019KY111); Foundation of Wenzhou City Science \& Technology Bureau (Y2020037, Y20180174); Zhejiang Provincial High-level Talents Program (2017102); Natural and Science Foundation of China (81570869); Wenzhou Key Team of Scientific and Technological Innovation (C20170002). The contribution of G.B. Bietti Foundation IRCCS was supported by the Italian Ministry of Health and Fondazione Roma. The funders had no role in study design, data collection and analysis, decision to publish, or reparation of the manuscript.

\section{Footnote}

Reporting Checklist: The authors have completed the STARD reporting checklist. Available at https://dx.doi. org/10.21037/atm-20-7895

Data Sharing Statement: Available at https://dx.doi. org/10.21037/atm-20-7895

Conflicts of Interest: All authors have completed the ICMJE uniform disclosure form (available at https://dx.doi. org/10.21037/atm-20-7895). The authors have no conflicts of interest to declare.
Etbical Statement: The authors are accountable for all aspects of the work in ensuring that questions related to the accuracy or integrity of any part of the work are appropriately investigated and resolved. The study was conducted in accordance with the Declaration of Helsinki (as revised in 2013). The study was approved by the Office of Research Ethical Committee, Eye Hospital of Wenzhou Medical University (No. KYK2013-21), and informed consent was obtained from all individual participants.

Open Access Statement: This is an Open Access article distributed in accordance with the Creative Commons Attribution-NonCommercial-NoDerivs 4.0 International License (CC BY-NC-ND 4.0), which permits the noncommercial replication and distribution of the article with the strict proviso that no changes or edits are made and the original work is properly cited (including links to both the formal publication through the relevant DOI and the license).

Open Access Statement: This is an Open Access article distributed in accordance with the Creative Commons Attribution-NonCommercial-NoDerivs 4.0 International License (CC BY-NC-ND 4.0), which permits the noncommercial replication and distribution of the article with the strict proviso that no changes or edits are made and the original work is properly cited (including links to both the formal publication through the relevant DOI and the license). See: https://creativecommons.org/licenses/by-nc-nd/4.0/.

\section{References}

1. Gordon MO, Beiser JA, Brandt JD, et al. The Ocular Hypertension Treatment Study: baseline factors that predict the onset of primary open-angle glaucoma. Arch Ophthalmol 2002;120:714-20; discussion 829-30.

2. Ambrosio R, Jr., Alonso RS, Luz A, et al. Cornealthickness spatial profile and corneal-volume distribution: tomographic indices to detect keratoconus. J Cataract Refract Surg 2006;32:1851-9.

3. Wang J, Fonn D, Simpson TL, et al. Relation between optical coherence tomography and optical pachymetry measurements of corneal swelling induced by hypoxia. Am J Ophthalmol 2002;134:93-8.

4. Randleman JB, Woodward M, Lynn MJ, et al. Risk assessment for ectasia after corneal refractive surgery. Ophthalmology 2008;115:37-50.

5. Randleman JB, Lynn MJ, Perez-Straziota CE, et al. 
Comparison of central and peripheral corneal thickness measurements with scanning-slit, Scheimpflug and Fourier-domain ocular coherence tomography. Br J Ophthalmol 2015;99:1176-81.

6. Prospero Ponce CM, Rocha KM, Smith SD, et al. Central and peripheral corneal thickness measured with optical coherence tomography, Scheimpflug imaging, and ultrasound pachymetry in normal, keratoconus-suspect, and post-laser in situ keratomileusis eyes. J Cataract Refract Surg 2009;35:1055-62.

7. Jonuscheit S, Doughty MJ. Discrepancy between central and midperipheral corneal thickness measurements obtained with slit-scanning pachymetry and noncontact specular microscopy. J Cataract Refract Surg 2009;35:2127-35.

8. Fares U, Otri AM, Al-Aqaba MA, et al. Correlation of central and peripheral corneal thickness in healthy corneas. Cont Lens Anterior Eye 2012;35:39-45.

9. Wegener A, Laser-Junga H. Photography of the anterior eye segment according to Scheimpflug's principle: options and limitations - a review. Clin Exp Ophthalmol 2009;37:144-54.

10. Hernandez-Camarena JC, Chirinos-Saldana P, Navas A, et al. Repeatability, reproducibility, and agreement between three different Scheimpflug systems in measuring corneal and anterior segment biometry. J Refract Surg 2014;30:616-21.

11. Shetty R, Arora V, Jayadev C, et al. Repeatability and agreement of three Scheimpflug-based imaging systems for measuring anterior segment parameters in keratoconus. Invest Ophthalmol Vis Sci 2014;55:5263-8.

12. Savini G, Carbonelli M, Sbreglia A, et al. Comparison of anterior segment measurements by 3 Scheimpflug tomographers and 1 Placido corneal topographer. J Cataract Refract Surg 2011;37:1679-85.

13. Bland JM, Altman DG. Statistical methods for assessing agreement between two methods of clinical measurement. Lancet 1986;1:307-10.

14. Buehl W, Stojanac D, Sacu S, et al. Comparison of three methods of measuring corneal thickness and anterior chamber depth. Am J Ophthalmol 2006;141:7-12.

15. Nam SM, Im CY, Lee HK, et al. Accuracy of RTVue optical coherence tomography, Pentacam, and ultrasonic pachymetry for the measurement of central corneal thickness. Ophthalmology 2010;117:2096-103.

16. Milla M, Pinero DP, Amparo F, et al. Pachymetric measurements with a new Scheimpflug photography- based system: intraobserver repeatability and agreement with optical coherence tomography pachymetry. J Cataract Refract Surg 2011;37:310-6.

17. Khoramnia R, Rabsilber TM, Auffarth GU. Central and peripheral pachymetry measurements according to age using the Pentacam rotating Scheimpflug camera. J Cataract Refract Surg 2007;33:830-6.

18. Martin R, Jonuscheit S, Rio-Cristobal A, et al. Repeatability of Pentacam peripheral corneal thickness measurements. Cont Lens Anterior Eye 2015;38:424-9.

19. Huang J, Ding X, Savini G, et al. A Comparison between Scheimpflug imaging and optical coherence tomography in measuring corneal thickness. Ophthalmology 2013;120:1951-8.

20. Kumar M, Shetty R, Jayadev C, et al. Repeatability and agreement of five imaging systems for measuring anterior segment parameters in healthy eyes. Indian J Ophthalmol 2017;65:288-94.

21. Cho P, Cheung SW. Central and peripheral corneal thickness measured with the TOPCON specular microscope SP-2000P. Curr Eye Res 2000;21:799-807.

22. Lu NJ, Chen D, Cui LL, et al. Repeatability of Cornea and Sublayer Thickness Measurements Using Optical Coherence Tomography in Corneas of Anomalous Refractive Status. J Refract Surg 2019;35:600-5.

23. Martin R, de Juan V, Rodriguez G, et al. Contact lensinduced corneal peripheral swelling: Orbscan repeatability. Optom Vis Sci 2009;86:340-9.

24. Jahadi Hosseini HR, Katbab A, Khalili MR, et al. Comparison of corneal thickness measurements using Galilei, HR Pentacam, and ultrasound. Cornea 2010;29:1091-5.

25. Anayol MA, Guler E, Yagci R, et al. Comparison of central corneal thickness, thinnest corneal thickness, anterior chamber depth, and simulated keratometry using galilei, Pentacam, and Sirius devices. Cornea 2014;33:582-6.

26. Huang J, Ding X, Savini G, et al. Central and midperipheral corneal thickness measured with Scheimpflug imaging and optical coherence tomography. PLoS One 2014;9:e98316.

27. De la Parra-Colin P, Garza-Leon M, Barrientos-Gutierrez T. Repeatability and comparability of anterior segment biometry obtained by the Sirius and the Pentacam analyzers. Int Ophthalmol 2014;34:27-33.

28. Nasser CK, Singer R, Barkana Y, et al. Repeatability of the Sirius imaging system and agreement with the Pentacam HR. J Refract Surg 2012;28:493-7. 
29. Mohamed S, Lee GK, Rao SK, et al. Repeatability and reproducibility of pachymetric mapping with Visante anterior segment-optical coherence tomography. Invest Ophthalmol Vis Sci 2007;48:5499-504.

Cite this article as: Yu AY, Ye J, Savini G, Wang Y, Zhang T, Chen M, Wang Q, Huang J. Reliability and agreement of the central and mid-peripheral corneal thickness measured by a new Scheimpflug based imaging. Ann Transl Med 2021;9(14):1136. doi: 10.21037/atm-20-7895
30. Bourges JL, Alfonsi N, Laliberte JF, et al. Average 3-dimensional models for the comparison of Orbscan II and Pentacam pachymetry maps in normal corneas. Ophthalmology 2009;116:2064-71. 